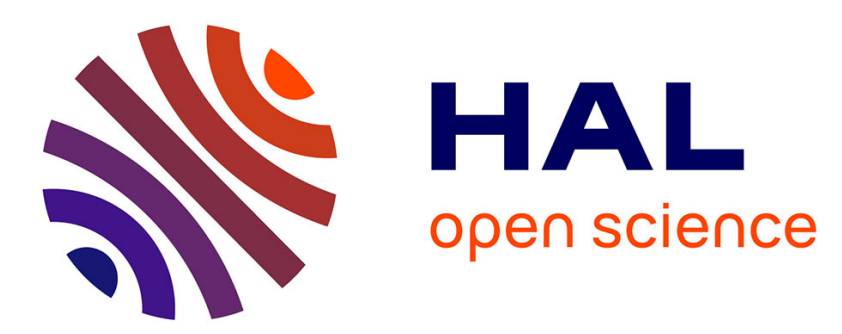

\title{
An analysis of fluid flows and solidification mechanisms during GTA welding by the means of in situ observations
}

Alexis Chiocca, Cyril Bordreuil, Fabien Soulie, Frédéric Deschaux-Beaume

\section{To cite this version:}

Alexis Chiocca, Cyril Bordreuil, Fabien Soulie, Frédéric Deschaux-Beaume. An analysis of fluid flows and solidification mechanisms during GTA welding by the means of in situ observations. Welding in the World, 2019, 10.1007/s40194-018-0673-8 . hal-02064915

\section{HAL Id: hal-02064915 \\ https://hal.science/hal-02064915}

Submitted on 12 Mar 2019

HAL is a multi-disciplinary open access archive for the deposit and dissemination of scientific research documents, whether they are published or not. The documents may come from teaching and research institutions in France or abroad, or from public or private research centers.
L'archive ouverte pluridisciplinaire HAL, est destinée au dépôt et à la diffusion de documents scientifiques de niveau recherche, publiés ou non, émanant des établissements d'enseignement et de recherche français ou étrangers, des laboratoires publics ou privés. 


\title{
An analysis of fluid flows and solidification mechanisms during GTA welding by the means of in situ observations
}

\author{
Alexis Chiocca $^{1} \cdot$ Cyril Bordreuil $^{1} \cdot$ Fabien Soulié $^{1} \cdot$ Frédéric Deschaux-Beaume $^{1}$
}

\begin{abstract}
Welding processes imply rapid solidification, in presence of high thermal gradient and strong fluid flows in the weld pool. This work presents, in the case of welding, an analysis of the coupling between solidification mechanisms and fluid flows at the macroscale and the microscale. An experimental setup was designed in order to observe in situ a fully penetrated weld pool generated on a Cu30Ni plate with a GTAW torch. At the macroscale, observations are carried out by three cameras: two cameras recording in visible light the top and the back side of the whole weld pool, and one infrared camera catching the thermal field on solid part at the back side. At the microscale, a high-speed camera, mounted with a microscope lens, is used to observe dendritic growth and fluid flows at the back side trailing edge of the weld pool. The observations provide a lot of data allowing analyses and discussions on the correlations between solidification mechanisms and fluid flows, with respect to welding parameters. Then, the experimental results are compared to theoretical results obtained from analytical modelling, in order to discuss the possible limitations of models and try to better understand the coupling between physical phenomena.
\end{abstract}

Keywords GTAW $\cdot$ Welding $\cdot$ Solidification $\cdot$ Fluid flow $\cdot$ In situ observation $\cdot$ High-speed camera

\section{Introduction}

The understanding of microstructure generation during welding is continuously in development. Because it mixes complex fields of physics such as solidification and fluid flows with the extreme conditions of welding, there are still many phenomena that are not understood. The multi-physical characteristics of solidification during welding make it hard to simulate and an accurate prediction of the final result is still not easy. Consequently, it is still difficult to obtain a microstructure that fits the required mechanical properties, without any defects such as centre line grain boundaries [1], porosities or inclusions [2], and the chosen welding parameters are often based on empirical experience. Therefore, solidification during welding is a complex phenomenon that needs to be investigated very carefully, in order to be able to produce the

Alexis Chiocca

alexis.chiocca@gmail.com

1 LMGC, Univ. Montpellier, CNRS, Montpellier, France desired microstructure and understand all the mechanisms that take place.

During welding, solidification conditions are very specific, because it is a rapid solidification regime, which is determined by high solidification rate, high thermal gradients, and strong fluid flows in the weld pool [3-6]. These physical phenomena have to be analysed on two scales. At the macroscale (the scale of the weld pool), solidification conditions change along the solidification front, making the microstructure morphology different from fusion line to centre line [3]. At the microscale, temperature conditions and fluid flows show a strong influence on the solidification process, by modifying the dendritic growth mechanisms [4, 7-9].

It is commonly admitted that solidification front morphology is mainly influenced by thermal conditions and solidification rate imposed by the process characteristics $[2,6]$. A decrease in the value of the ratio of thermal gradient over solidification rate gradually modifies solidification front morphology, from planar to cellular, columnar dendritic, and finally equiaxe dendritic. In addition, the product between thermal gradient and solidification rate plays a role on dendrite arm sizes and spacing. The presence of fluid flow has also been found to have a determinant impact on solidification behaviour. Several studies show a modification in 
solidification rate and direction with intensity and direction of the fluid flow in the vicinity of the solidification front. The flow alters heat and solute exchanges around dendrites, which change growth conditions of dendrites $[4,7,9]$. Thus, some growth direction or growth areas can be promoted at the expense of others.

In the case of welding, at the macroscale, from the trailing edge of the weld pool to the fusion line, it is well known that solidification rate decreases and thermal gradient increases, producing changes in microstructure, such as morphology transitions $[2,5]$. At this scale, the fluid flow is known to influence the shape of the weld pool $[2,10]$.

The present article aims at better understanding the link between physical phenomena occurring in the weld pool, thanks to experimental data obtained by the means of in situ observations and measurements on two scales. The discussions about these measurements are enriched by a solidification model applied to welding conditions.

\section{Experimental setup}

An experimental setup has been designed to investigate physical phenomena on the two scales. It is an upgrade of a setup, detailed in a previous publication [11], which now includes a moving support (Fig. 1). A GTAW torch generates a fully penetrated weld pool on a $1.6-\mathrm{mm}$ thick plate of $\mathrm{Cu} 30 \mathrm{Ni}$. The plate dimensions are $150 \times 70 \mathrm{~mm}^{2}$ and the weld lines produced by translation of the support are 10-cm long. Both sides of the plate are protected by a pure argon gas. The tests have been carried out with tungsten electrodes enriched with
$2 \%$ of lanthanide, of $1.6-\mathrm{mm}$ diameter and $30^{\circ}$ grinding angle. The welding parameters have been chosen to obtain several sets of parameters filling the condition of a fully penetrated weld pool, without any collapse of liquid. The weld pool is only maintained by surface tension. Welding parameters have been monitored using a voltmeter and a LEM, and are referenced in Table 1.

Macroscopic observations of fluid flows and weld pool shape are made by two AVT cameras. They record in visible light the back side and the top side of the weld pool (in red on Fig. 1). Temperature field in the solid part of the plate around solidification front is measured on the back side of the sample, thanks to an infrared camera. Temperature calibration of the images of this camera is made with the help of two thermocouples placed in base metal on the back side of the plate. A third thermocouple is monitoring temperature of the support. During tests, microscopic observation is made on the back side at the trailing edge of the weld pool by a high-speed camera (5000 fps) and a microscope lens. The observation areas are red framed on Fig. 1(a)-(c). All the measurements are synchronised in time.

All the methods used to process the videos and extract the key measurements (thermal gradient, solidification rate, and fluid flow) are described in more detail in a previous publication [11].

\section{Experimental results}

At the macroscale, infrared and visible observations on back side have been executed simultaneously to measure at the

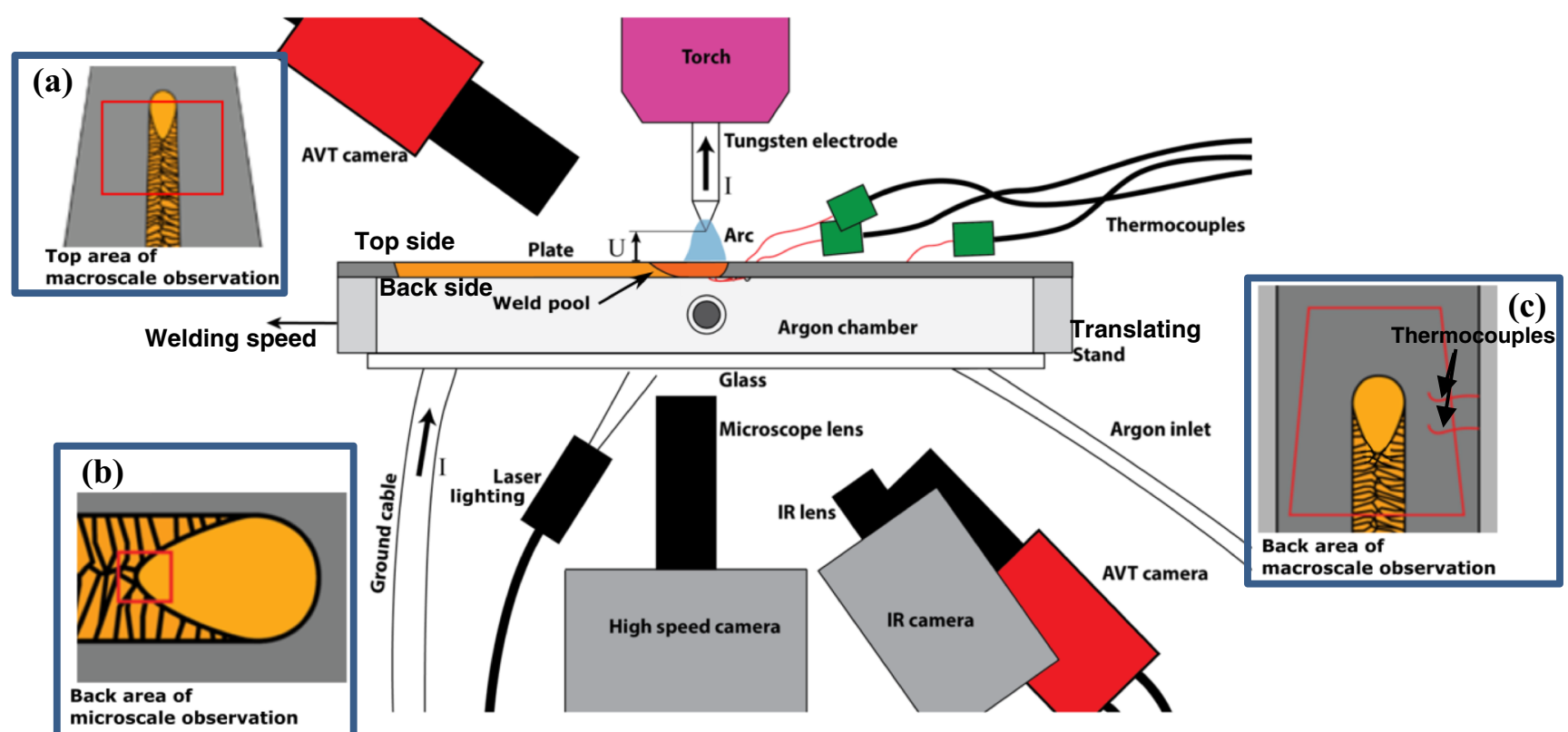

Fig. 1 The experimental setup. Red framed areas at (a), (b), and (c) represent respectively the observation areas of the top AVT camera, the high-speed camera, and the back IR and AVT cameras 
Table 1 Welding parameters used for the tests (mean values)

\begin{tabular}{lllll}
\hline Test & Heat input $(\mathrm{J} / \mathrm{mm})$ & Welding speed $(\mathrm{mm} / \mathrm{s})$ & Voltage $(\mathrm{V})$ & Current $(\mathrm{A})$ \\
\hline 1 & 285 & 3 & 9.3 & 92.5 \\
2 & 219 & 3 & 8.5 & 77.3 \\
3 & 202 & 4.3 & 9.4 & 92.6 \\
\hline
\end{tabular}

same time thermal gradient and solidification rate along the solidification front, from trailing edge to fusion line. An example of a temperature map of test 1 is given in Fig. 2a. From Fig. 2a image, thermal data can be extracted to result in thermal gradient evolution along the solidification front given in Fig. 2b. As it is expected from theory, measured thermal gradient increases and measured solidification rate decreases between these two points for the three tests (Table 2 and Fig. 2b). The various observed weld pool shapes during tests are also in accordance with the theory. A higher welding speed (between tests 1 and 3) produces a longer and narrower weld pool and a lower current (between tests 1 and 2) produces a shorter and narrower one (Table 2). At the trailing edge, thermal gradient is rather similar between tests 1,2 , and 3 (Fig. 2b), while increase of the welding speed between tests 1 and 3 and increase of the current between tests 2 and 1 should have led to a lower thermal gradient. Welding parameters (intensity and welding speed) should probably be changed in a larger range to obtain significant differences in thermal gradient measurements. However, lower heat input produces a partially penetrated weld pool and increase it makes the weld pool collapse. Meanwhile, the applied reduction of heat input seems to reduce the thermal gradient at the fusion line. This could be caused by a lesser temperature homogenisation of the weld pool, due to lower fluid flows when heat input decreases. The values of undercooling measurements in Table 2 show a significant increase of undercooling from tests 1 and 2 to test 3 . It seems to verify the relation between solidification rate, corresponding to welding speed at the trailing edge, and undercooling $v(\Delta T)[1,4]$, that is to say the undercooling increases with solidification rate.

At the macroscale, observations of fluid flows revealed rotational movements. In Fig. 3, the images extracted from the videos, on the top and back sides, show symmetrical rotations of two oxides clusters on both sides of the weld pool and in the same direction. This could reveal the occurrence of a fluid flow going from front centre of the weld pool to the trailing edge, following the edges of the weld pool. Then, this flow seems to go back to the front by the centre line of the weld pool, producing the observed circulation (Fig. 3).

The observation of the solidification front at microscale reveals several phenomena. Dendritic growth at the trailing edge recorded in situ during welding is shown on Fig. 4 and Fig. 5a. On the left part of this figure, primary dendritic arms growing into the weld pool are observed. This part is not homogeneous, it is fully or quasi-solid on the left top and bottom corner, but by reaching the weld pool, in the semisolid region, the liquid part becomes more and more important. Between results obtained with the three welding parameters, no significant differences have been found in the interdendritic spacing or the size of the semi-solid area (Fig. 4). The only noted difference was the shape of the trailing edge, confirmed by macroscale observations on the back side. It is sharper when welding speed increases.

Thanks to little oxide particles naturally present in the weld pool, fluid flows characteristics have been observed and
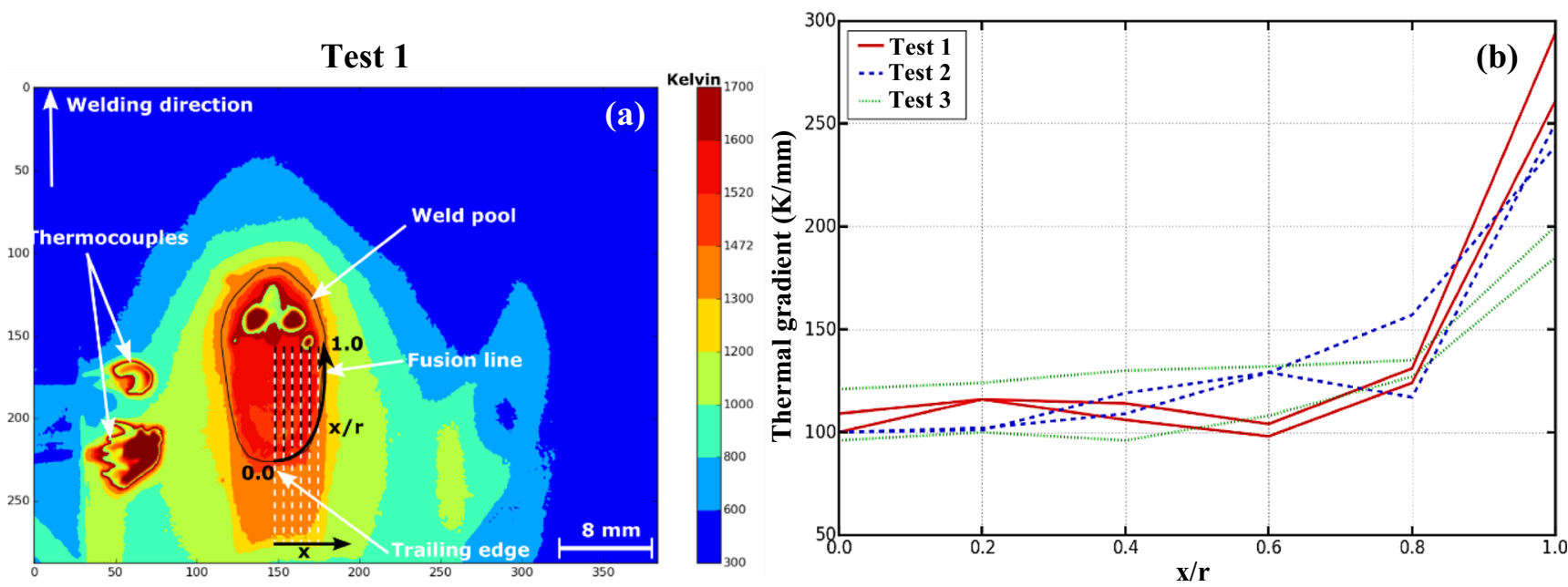

Fig. 2 a Temperature map extracted from IR camera data of test $1, \mathbf{b}$ evolution of thermal gradient along solidification front from trailing edge to fusion line (the curves of the three tests are plotted). In the ratio $\frac{x}{r}, r$ is the half width of the weld bead 
Table 2 Geometrical and thermal measurements at macroscale (mean values)

\begin{tabular}{|c|c|c|c|c|c|c|}
\hline Test & $\begin{array}{l}\text { Trailing edge } \\
\text { gradient }(\mathrm{K} / \mathrm{mm})\end{array}$ & $\begin{array}{l}\text { Fusion line } \\
\text { gradient }(\mathrm{K} / \mathrm{mm})\end{array}$ & $\begin{array}{l}\text { Undercooling } \Delta T \text { at the } \\
\text { trailing edge }(\mathrm{K})\end{array}$ & $\begin{array}{l}\text { Weld pool width on the } \\
\text { top side }(\mathrm{mm})\end{array}$ & $\begin{array}{l}\text { Weld pool width on the } \\
\text { back side (mm) }\end{array}$ & $\begin{array}{l}\text { Weld pool length on the } \\
\text { back side (mm) }\end{array}$ \\
\hline 1 & 105 & 278 & 66 & 8.3 & 8.0 & 15.2 \\
\hline 2 & 100 & 245 & 71 & 5.4 & 4.5 & 8.1 \\
\hline 3 & 109 & 196 & 207 & 5.8 & 5.1 & 11.9 \\
\hline
\end{tabular}

measured at the microscale with a good accuracy (Stoke numbers calculated are around 0.1). Particles are seen appearing in liquid channels between primary dendrite arms, flowing from the root of the semi-solid area to reach the entirely liquid weld pool (Fig. 5b). The trajectories of these particles suggest the presence of a fluid flow in the semi-solid region. The measurements of the velocity of these particles, supposed to be equal to fluid flow velocity, done by PTV (Particle Tracking Velocity [11]) show an evolution of fluid flow characteristics between the root of liquid channels and the liquid pool. Figure 6a shows the velocity of particles from the inside of liquid channels to fully liquid weld pool for the three welding parameters. It reveals that fluid flow velocity is low (between 60 and $100 \mathrm{~mm} / \mathrm{s}$ ) in channels, but when they reach the limit of the semi-solid area (solidification front), they are accelerated to a higher velocity (between 110 and $180 \mathrm{~mm} / \mathrm{s}$ ). This implies that there are two different fluid circulations near the trailing edge of the weld pool (Fig. 6b): one flow into the liquid pool going from top side trailing edge of the weld pool to back side, and another flow following the same direction but crossing the semi-solid region.

Between test 2 and the two other tests, flow velocity evolution into the weld pool is different (Fig. 6a). The velocities are rather equivalent in the semi-solid region, but the fluid acceleration is more important after solidification front, for test 2 . This result seems surprising since it is generally considered that the flows in the weld pool are governed mainly by the Marangoni effect (surface tension gradient due to temperature gradient on the surface of the weld pool), which increases with heat input, whereas test 2 is not the one carried out at the highest heat input. However, weld pools of tests 1 and 3 have sharper trailing edge than test 2 (Table 2), which can produce a fluid flow deceleration at the trailing edge, that is less important for test 2 , due to the more rounded shape of the trailing edge. The discrepancy of fluid flow velocity of test 2 is probably caused by the inaccuracy of locations of dendrite tips and solidification front at the trailing edge.

Figure $6 \mathrm{~b}$ shows schematically, on a longitudinal section, the rotating clusters observed in the weld pool at macroscale (Fig. 3). The rotation of the clusters occurs in the same direction on top side and back side of the weld pool. It can be supposed that rotations are present in the whole thickness of the weld pool as it is illustrated on Fig. 6b.

Reynolds numbers have been calculated between primary dendrite arms and in the liquid pool using data extracted at the microscale. Whatever the test, Reynolds number is about 20 between dendrite arms, increases to about 420 around solidification front limit, and reaches a maximal value of about 1150 in the weld pool on the viewing area of microscale images. In the three areas, Reynolds number is pretty low seeming to indicate that the flow is laminar at the trailing edge of the weld pool.

\section{Discussion}

A combination of the observations at the macroscale and at the microscale allows to draw a map of fluid flows in the whole

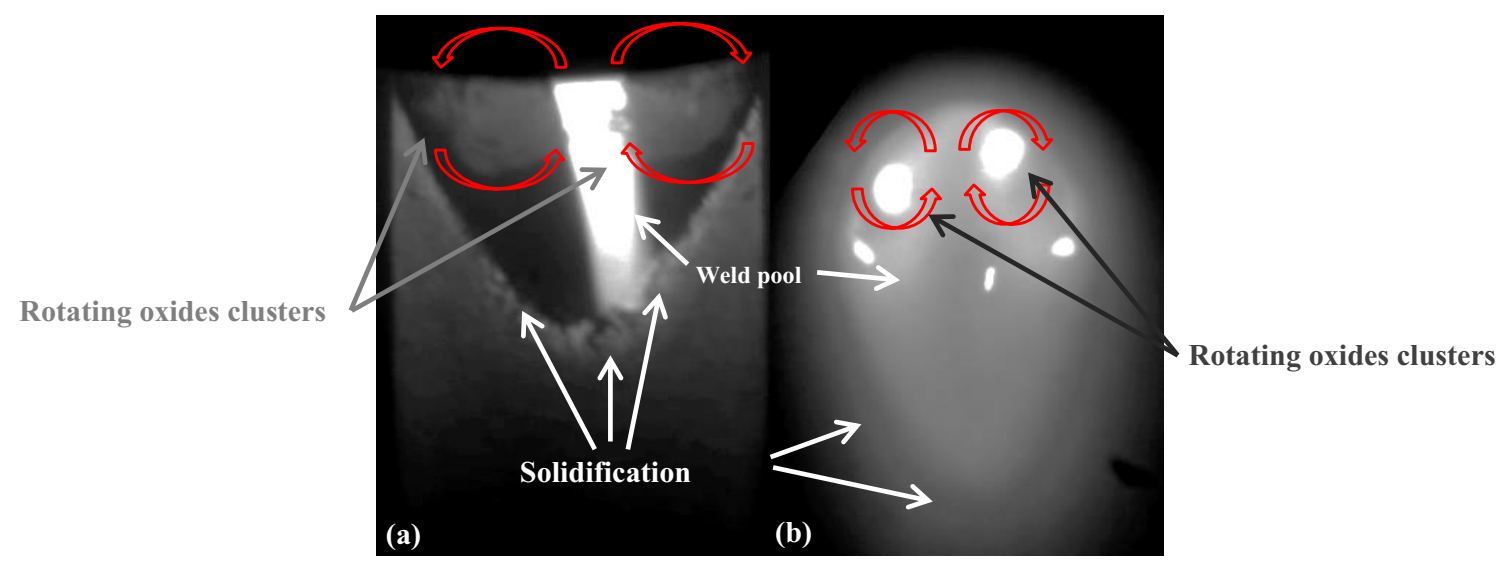

Fig. 3 (a) Top view of the weld pool, (b) bottom view of the weld pool 

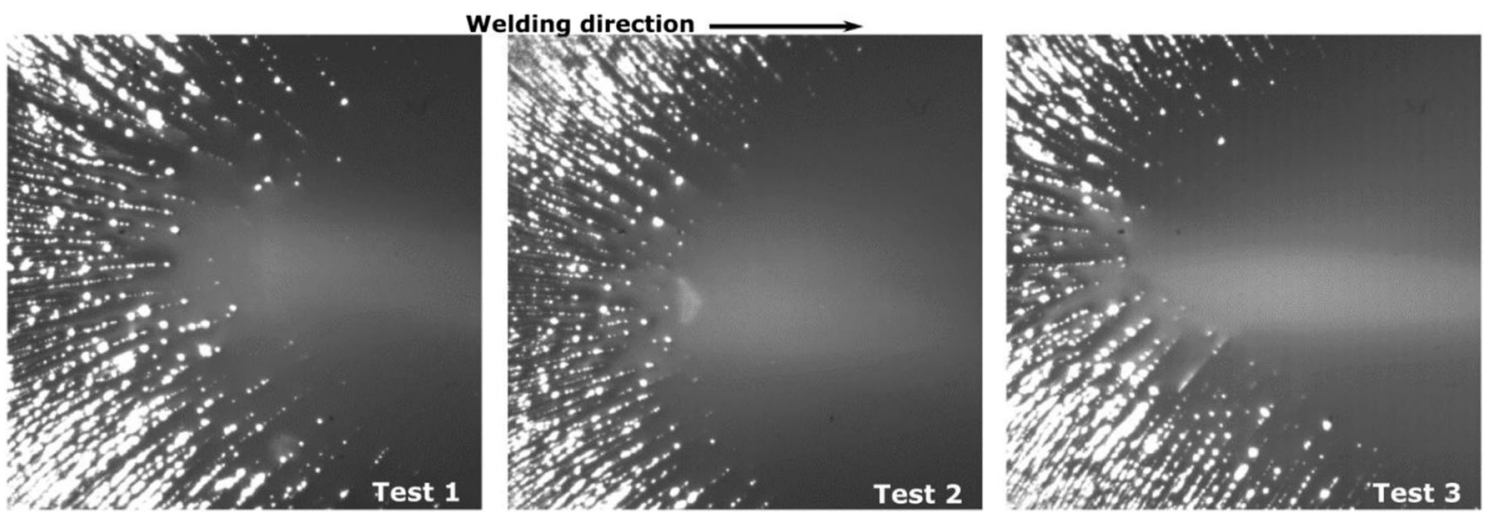

Fig. 4 Three images taken at the same scale coming from high-speed camera videos. From left to right, back side trailing edge of the weld pools of tests 1,2 , and 3

weld pool. Figure 7 shows on the two sides suggested fluid flow mapping. On the top side (Fig. 7a), Marangoni effect, which is commonly the predominant force generating fluid flow in welding, drives the liquid from the hottest area (under the arc) to the edges of the weld pool, which are colder. Then, the liquid is pushed from the fusion line to the trailing edge by flowing along the solidification front. The flow is then separated in three components: the first one returns to the weld pool centre on top side, leading to rotations of the two oxides clusters; the second one goes through the thickness of the weld pool to the back side in the liquid area; finally, the third one goes through the thickness of the weld pool to the back side in the semi-solid area. On back side of the weld pool (Fig. 7b), the liquid coming from the semi-solid area and its vicinity goes from the rear of the weld pool to the centre. Finally, the flow produces the rotations of the oxides and goes back to the top side.

The macroscopic thermal flow Péclet number $\left(\mathrm{Pe}_{\mathrm{th}}=\frac{u L_{\mathrm{c}}}{\alpha}\right.$, with $u$ the fluid flow velocity, $L_{\mathrm{c}}$ a characteristic length, and $\alpha$ the thermal diffusivity), which represents the ratio between thermal convection and thermal conduction, calculated at weld pool scale is between 50 and 100. These values and the fluid flow mapping (Fig. 7a) highlight the fact that fluid flows in the weld pool are mainly responsible for heat transfer from the front of the weld pool to the trailing edge. Heat transfer from the front to the trailing edge helps to homogenise temperature and can be one of the causes of the characteristic shape of solidification front. It is illustrated on Fig. 8(a). The hot liquid flows on top side to the trailing edge, retarding solidification and elongating the weld pool. By flowing through the semi-solid area from top side to back side, the liquid is cooled. Solidification is then less retarded in the back side, and the weld pool rear is less elongated.

The fluid flow has not only an effect on heat transfer. As it is seen in many publications $[4,7]$, solute concentration in the vicinity of growing dendrites has an effect on the growth velocity. If solute concentration is locally modified in the liquid near the surface of growing dendrites, solidification rate would be changed. In the case of this study, fluid flow observed in the vicinity of dendrites arms and deduced flow in the whole semi-solid region could then influence solidification. The microscopic solutal flow Péclet number $\left(\mathrm{Pe}_{\mathrm{C}}=\frac{u L_{\mathrm{c}}}{D_{1}}\right.$, with $u$ the fluid flow velocity, $L_{\mathrm{c}}$ a characteristic length, and $D_{1}$ the diffusivity coefficient of the solute) calculated using dendrite spacing as characteristic length is greater than one.

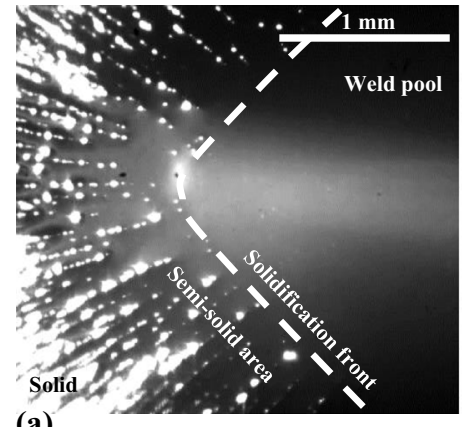

(a)

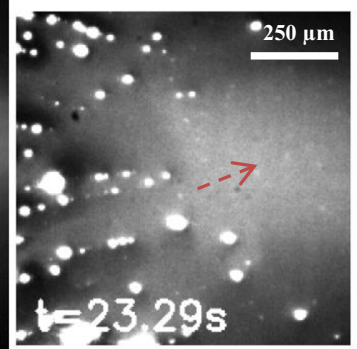

(b)
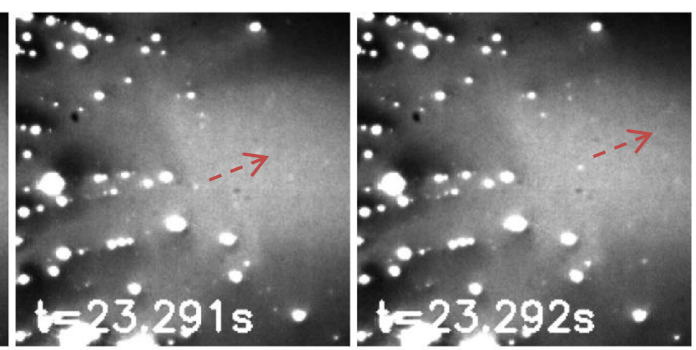

Fig. 5 a Microscale view of the trailing edge of the weld pool showing primary dendrite arms growing into the liquid; $\mathbf{b}$ three images taken every millisecond of the semi-solid area showing displacement of particles in liquid channels 

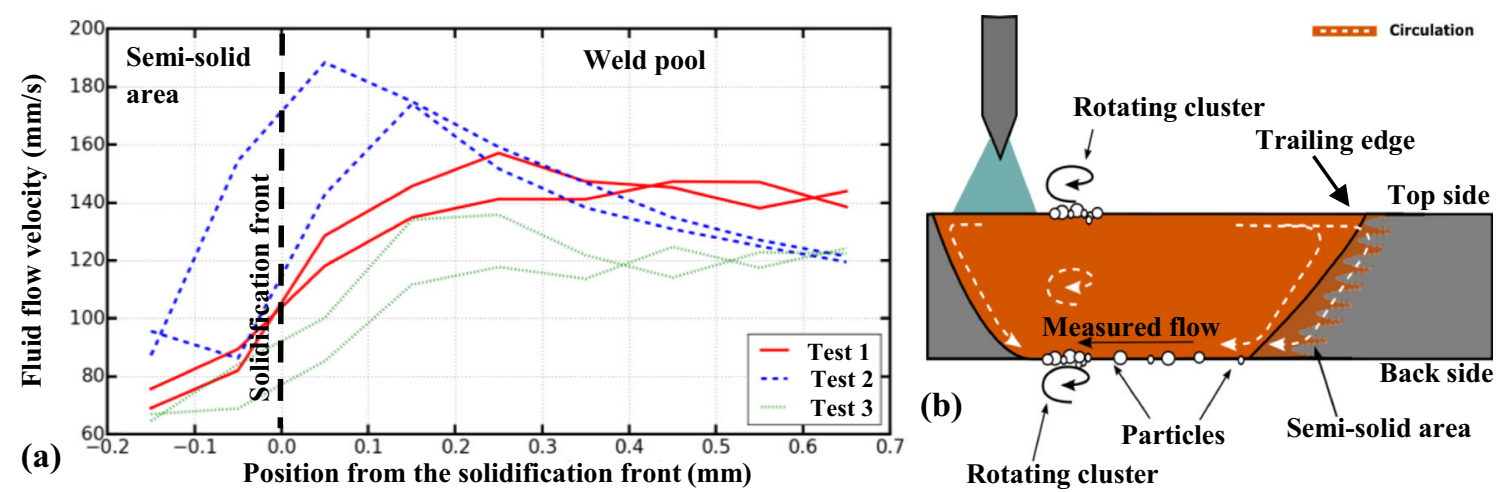

Fig. 6 a Fluid flows velocity evolution from the semi-solid region to the weld pool for the three welding parameters (the 0 origin is the solidification front limit); $\mathbf{b}$ illustration of fluid flows in a longitudinal section of the weld pool during welding

Therefore, solute transfer in the liquid near growing dendrites is mainly controlled by fluid flow.

As partition coefficient (ratio between solute concentration in solid and liquid phases) of the $\mathrm{Cu} 30 \mathrm{Ni}$ alloy is superior to 1 , the liquid coming from the top trailing edge of the weld pool is solute rich or at initial concentration (Fig. 8(a)). At the opposite, the liquid coming from the semi-solid area could be solute poor (Fig. 8(b)), because solute is absorbed by dendrites during solidification. Consequently, between top and back side of the semi-solid area, the liquid could be more and more solute poor, decreasing the primary dendrite arms growth velocity, and retarding solidification on back side. This phenomenon is not observed. It seems to indicate that the effect of thermal convection is predominant with respect to the effect of solute transfer at the macroscale. However, the solute impoverishment can influence size or growth velocity of secondary dendrite arms. On videos recorded at the microscale on back side, only very long primary dendrite arms, without secondary dendrite arms, have been observed. It can be caused by the solute poor liquid flowing between dendrite arms, slowing down the growth of secondary arms.

\section{Model comparison}

In order to improve our understanding of the coupling between fluid flows and solidification mechanisms observed and analysed in the previous sections, analytical models have been developed. The comparison between the results extracted from these analytical models and experimental results can better explain the coupling between solidification and fluid flows and helps predictions of the solidification behaviour during welding. If predictions are accurate enough and the model is applied to more common materials, it could be a first step to promote development of contribution in order to propose models usable in the industrial sector.
Fig. 7 Fluid flow mapping a on the top side of the weld pool and $\mathbf{b}$ on the back side of the weld pool. The fluid flows are coded by origin in three colours
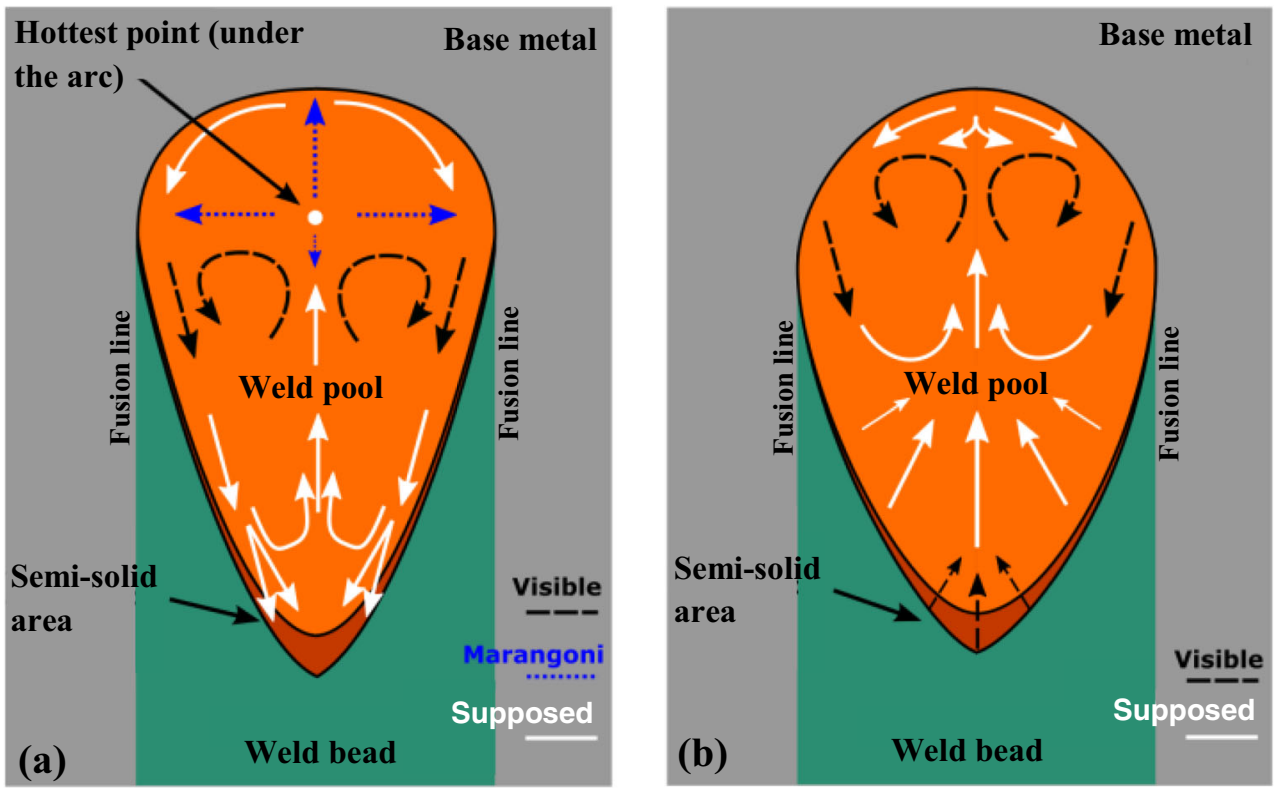
Fig. 8 (a)-(c) The effects of the fluid flows on the solidification front (a)

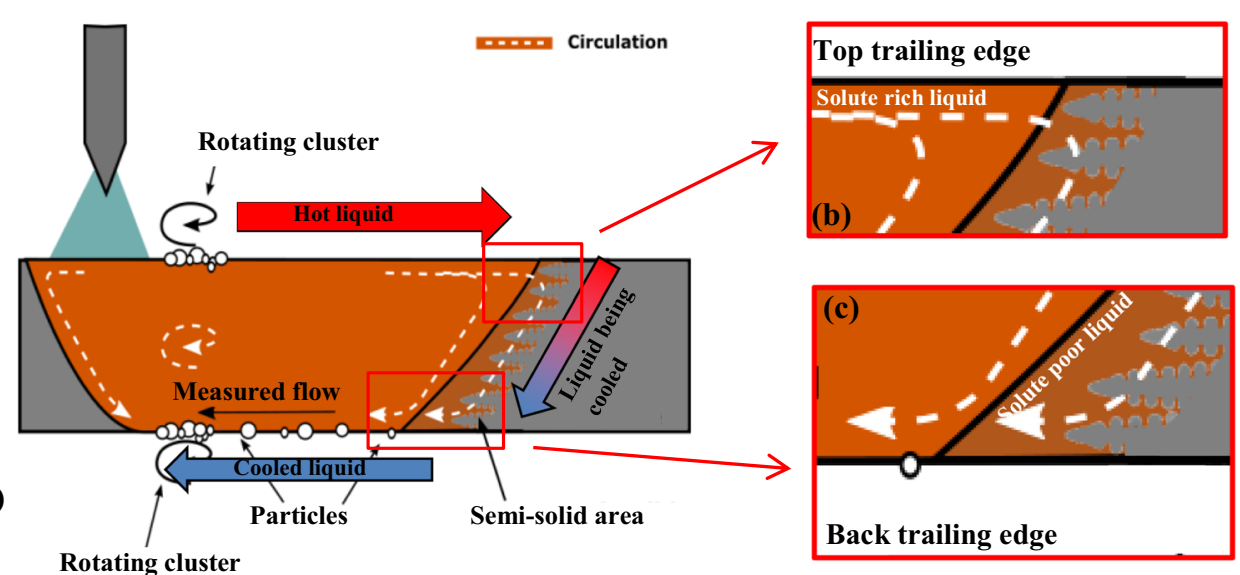

\subsection{Analytical model composition}

The models used in this article are adapted from the one developed by Gandin et al. [4], which is based on a classic KGT model (Kurz, Giovanola, and Trivedi) [12]. These models express the relations between dendrite tip radius, solidification rate, and undercooling in the liquid adjacent to the dendrite tip. The contribution of the Gandin et al. model is the introduction of a liquid boundary layer around growing dendrites in front of solidification front, aiming at taking into account the contribution of the fluid flow into the solutal equilibrium near the solid/liquid interface. In this model, solute transfer mechanisms are supposed diffusion controlled inside the boundary layer, whereas liquid composition is supposed uniform outside, due to fluid flow. The thickness of the boundary layer changes depending on fluid flow conditions, such as intensity and direction, in the vicinity of the growing dendrites.

Gandin et al. model is, however, not suited for rapid solidification, corresponding to high solutal Peclet number $P_{v}$ $\left(P_{v}=\frac{v R}{2 D_{1}}\right.$, with $v$ the dendrite tip velocity, $R$ the dendrite tip radius, and $D_{1}$ the diffusivity coefficient), as in the case of the present study. The following relations, derived from the rapid solidification KGT model, are then used [6]:

$$
\begin{aligned}
R & =2 \pi \sqrt{\frac{\Gamma}{m_{1} G_{\mathrm{Cl}} \xi_{\mathrm{c}}-G}} ; G_{\mathrm{Cl}}=-\frac{v}{D_{1}}\left(\frac{C_{0}(1-k)}{1-\Omega(1-k)}\right) ; \xi_{\mathrm{c}} \\
& =\frac{1-\sqrt{1+\left(\frac{2 \pi}{P_{v}}\right)^{2}}}{1-\sqrt{1+\left(\frac{2 \pi}{P_{v}}\right)^{2}-2 k}} ;
\end{aligned}
$$

with $\Gamma$ the Gibbs-Thomson coefficient, $m_{1}$ the liquidus slope, $G_{\mathrm{Cl}}$ the solutal gradient in the liquid at solid/liquid interface, $\xi_{\mathrm{c}}$ a rapid solidification coefficient, $G$ the thermal gradient in the liquid at the solid/liquid interface, $C_{0}$ the initial solute concentration, $k$ the equilibrium partition coefficient, and $\Omega$ the sursaturation. This last term is expressed as following to take into account the fluid flow, according to Gandin et al. model:

$$
\begin{aligned}
\Omega & =P_{v} \exp \left(P_{v}\right)\left(E_{1}\left(P_{v}\right)-E_{1}\left(P_{v}\left(1+\frac{2 \delta}{R}\right)\right)\right) ; \delta \\
& =\frac{2 R}{\mathrm{Sh}-2} ; E_{1}(u)=\int_{u}^{\infty} \frac{\exp (-s)}{s} d s ;
\end{aligned}
$$

Sh is the Sherwood number: $\mathrm{Sh}=2+A \operatorname{Re}^{B} \mathrm{Sc}^{C} f(\theta)$; $\operatorname{Re}=2 \frac{R u}{v}=4 \frac{P_{u} \cdot D l}{v} ; \mathrm{Sc}=\frac{\nu}{D 1}$ with $f=\sin \left(\frac{\theta}{2}\right)$ a function that takes into account the angle $\theta$ between the directions of the fluid flow and the dendritic growth (the same used by Gandin et al. [4]), $u$ the velocity of the fluid flow with respect to the dendritic tip, $P_{u}=\frac{R u}{2 D_{l}}$ the flow Péclet number, $\mathrm{Sc}=\frac{\nu}{D_{1}}$ the Schmidt number with $\nu$ the kinematic viscosity, $A, B$, and $C$ factors calculated in the same way as Gandin et al. [4] and $\delta$ the thickness of the boundary layer in front of the solidification front.

By numerically resolving the equation system composed of Eqs. (1) and (2) and introducing the following formulation of the undercooling $\Delta T$ (Eq. 3), a relationship between $\Delta T$ and the growth velocity of the dendrites tip $v, v(\Delta T)$, has been found.

$$
\Delta T=\Delta T_{\mathrm{C}}+\Delta T_{\mathrm{R}}=m_{\mathrm{l}} C_{0}\left(1-\frac{1}{1-(1-k) \Omega}\right)+\frac{2 \Gamma}{R} ;
$$

Parameters $\Delta T_{\mathrm{C}}$ and $\Delta T_{\mathrm{R}}$ correspond respectively to the constitutional and curvature undercooling.

On Fig. 9a, we can see a comparison between two curves $v(\Delta T)$, resulting from simulations using the Gandin et al. original model and the model adapted to our welding conditions. Parameters used for these simulations are given in Table 3. One can see until a $\Delta T$ of $16 \mathrm{~K}$, the curves are rather similar, but from $20 \mathrm{~K}$, the solidification rate becomes lower for a 


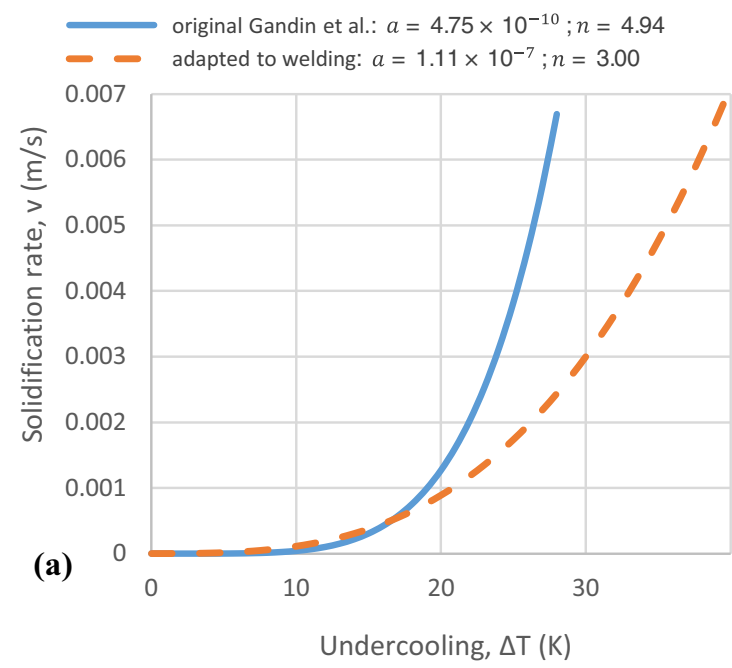

Fig. 9 Curves illustrating the relationship between dendrite tip growth velocity $v$ and undercooling $\Delta T$, a comparison of results from the original Gandin et al. model and from the adapted model with no fluid flow and $\mathbf{b}$

given undercooling with the adapted model. These curves can be approached by a power function: $v(\Delta T)=a . \Delta T^{n}$. The parameters of these functions are given in Fig. 9. Figure 9b shows the effect of the variation of the fluid flow velocity $u$, for a flow in the opposite direction of the dendritic growth direction (i.e. corresponding to $\theta=2 \pi$ in the Sherwood number) on the results of the simulation for the adapted model. If fluid flow velocity has no significant effect for low velocities (up to $10 \mathrm{~mm} / \mathrm{s}$ ), it increases the growth rate of dendrites tip for a given undercooling when the fluid flow velocity is high.

\subsection{Confrontation with the experimental data}

The adapted model predicts for the two tested velocities $3 \mathrm{~mm} / \mathrm{s}$ and $4.3 \mathrm{~mm} / \mathrm{s}$, corresponding to tests 1 and 3 (cf. Table 1), respectively undercooling of $30 \mathrm{~K}$ and $34 \mathrm{~K}$ at the trailing edge of the weld pool (Fig. 9a). The measurements show an undercooling much greater of respectively $66 \mathrm{~K}$ and $207 \mathrm{~K}$ (cf. Table 2). In order to try to improve the fit between modelling and experiment, the adapted model has to be revised.

The observed fluid flows along the growing dendrites at the trailing edge of the weld pool have the same direction than the growth direction of dendrites. In this case, the adapted model does not take into account an influence of fluid flow on dendritic growth velocity $(f(\theta)=0$, Eq. (2)). However, this flow should have an influence on growth mechanism, because it produces an impoverishment of the liquid coming from the dendrites foot (see Section 4). The composition of the liquid at the dendrite tip could be then more solute poor than equilibrium composition of the liquid at liquidus temperature. To consider the effect of fluid flow in growth direction of dendrites in the adapted model, the partition coefficient $k$ has been

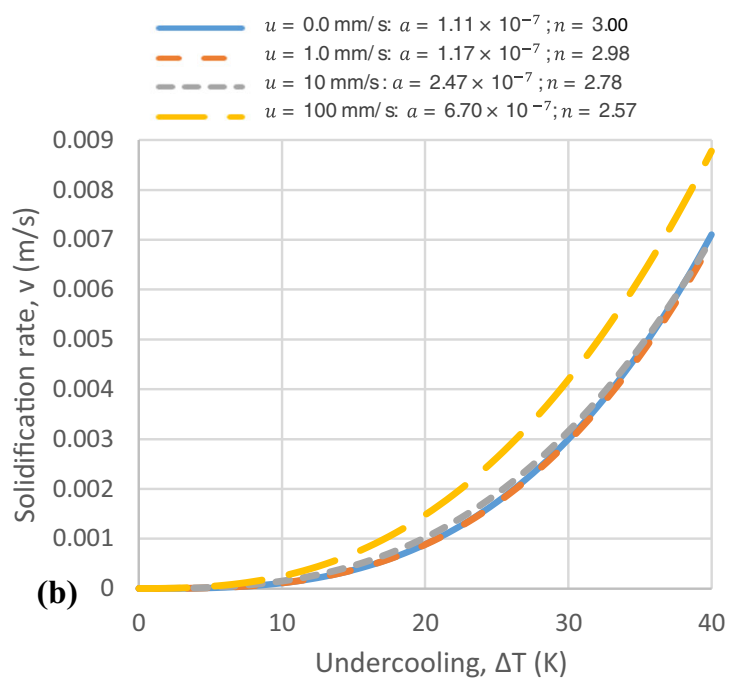

results from the adapted to welding model with variation of the fluid flow velocity $u$ in the opposite direction of dendritic growth direction

artificially modified. By increasing the partition coefficient from 1.4 to 2.2 , corresponding to the ratio between solute content in the solid at liquidus temperature and solute content in the liquid at solidus temperature (i.e. liquid composition at dendrite foot), it is possible to obtain a curve $v(\Delta T)$ giving lower velocity with high level of undercooling, as experimental measurements suggest. The evolution curve $v(\Delta T)$ resulting from a simulation realised with this revised model (named $\mathrm{k}$ modified model) is compared to the one resulting from the original model on Fig. 10. With this revised model, the corresponding values of undercooling for the two tested velocities, $3 \mathrm{~mm} / \mathrm{s}$ and $4.3 \mathrm{~mm} / \mathrm{s}$, are $50 \mathrm{~K}$ and $56 \mathrm{~K}$ respectively. The revised model is in good agreement with the experimental undercooling at $3 \mathrm{~mm} / \mathrm{s}$ but in the case of $4.3 \mathrm{~mm} / \mathrm{s}$, the calculated value is still very low compared to experiment.

The comparison between simulation and experiment has only been done at the trailing edge of the weld pool. It can

Table 3 Physical parameters used for the calculation of all the simulations of this study

\begin{tabular}{ll}
\hline Parameters & Values \\
\hline Gibbs-Thomson coefficient, $\Gamma(T=1550 \mathrm{~K})$ & $8.1 .10^{-1} \mathrm{~K} \mathrm{~m}$ \\
Liquidus slope, $m_{l}$ & $3.9 \mathrm{~K} / \mathrm{wt} \%$ \\
Initial concentration, $C_{0}$ & $30 \mathrm{wt} \%$ \\
Diffusion coefficient Ni -> L, $D_{l}$ & $1.10^{-9} \mathrm{~m}^{2} / \mathrm{s}$ \\
Partition coefficient, $k$ & 1.4 \\
Thermal gradient, $G$ & $300.10^{3} \mathrm{~K} / \mathrm{m}$ \\
Dendrite tip radius, $\mathrm{R}$ & $0.001 \mathrm{~mm}$ \\
A & 0.5773 \\
B & 0.6596 \\
C & 0.5249 \\
\hline
\end{tabular}


Fig. 10 Comparison between the calculated curves $v(\Delta T)$ from simulations with the Gandin et al. model, the adapted model, and the k-modified model

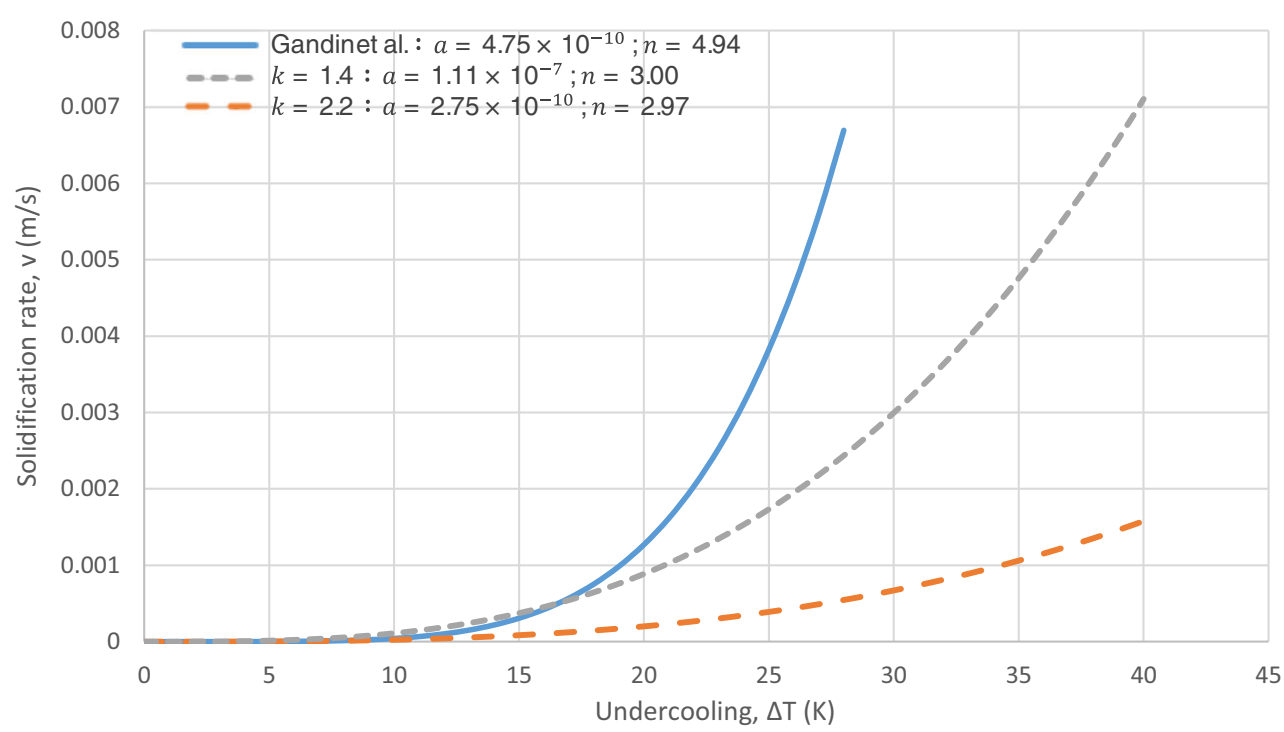

be extended to the entire solidification front by building a modelised front from thermal fields, the growth function $v(\Delta T)$, and the relation between the growth velocity $v$ and the welding velocity $v_{s}$. This technique is inspired from the modelling suggested by Hunziker et al. [1]. The thermal field is predicted using the classical Rosenthal model $[5,13]$, in which heat source efficiency is identified to obtain the same weld pool width as with experimental tests.

The relation between dendritic front velocity $v$ and welding speed $v_{s}$ is expressed in Eq. (4).

$v=v_{s} \cos (\alpha)$

with $\alpha$ the angle between the welding direction and the normal to solidification front.

To locate the solidification front on the whole weld pool, Eq. (4) is coupled with the equations giving the growth rate versus the undercooling, identified from the various models (Eq. (5)):

$v(\Delta \mathrm{T})=a \Delta T^{n}=a\left(T_{\mathrm{liq}}-T(x, y)\right)^{n} ;$

with $T_{\text {liq }}$ the temperature of the liquidus of the studied alloy and $T(x, y)$ the temperature at the solidification front (i.e. at the dendrites tip), located at the position $(x, y)$ on the plate to be welded. Considering $y(x)$ as the contour of the solidification front in the plan of the plate to weld, the function $y^{\prime}(x, y)$ corresponds to the tangent of the solidification front. Therefore, the angle $\alpha$ can be then expressed as:

$$
\begin{gathered}
\operatorname{cotan}(\alpha)=y^{\prime}(x, y) \\
\cos (\alpha)=\cos \left(\operatorname{arccotan}\left(y^{\prime}(x, y)\right)\right)=\frac{y^{\prime}(x, y)}{\sqrt{1+y^{\prime}(x, y)}} ;
\end{gathered}
$$

Fig. 11 Comparison of the observed weld pools with the liquidus isotherm contours and solidification front contours computed from the Hunziker method using the adapted to welding growth model and the $\mathrm{k}$ modified growth model, for the three tested conditions (Table 1)

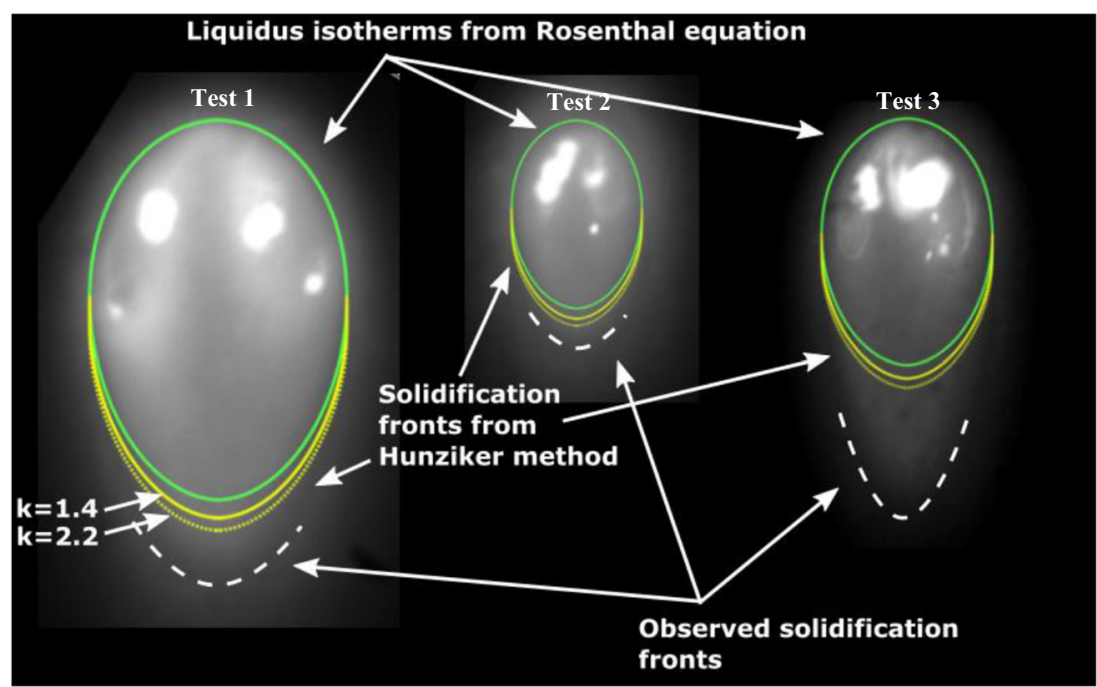


From this equation, it can be deduced by isolating $y^{\prime}(x, y)$ :

$y^{\prime}(x, y)=\frac{a\left(T_{\mathrm{liq}}-T(x, y)\right)^{n}}{\sqrt{v_{s}^{2}-a^{2}\left(T_{\mathrm{liq}}-T(x, y)\right)^{2 n}}} ;$

A numerical resolution of Eq. (6), with the help of Eqs. (3) and (4), allows finding a valid solution for the contour of the solidification front $y(x)$. A contour plot of this solidification front is visible in yellow on Fig. 11, compared to calculated liquidus isotherm contour, obtained using the Rosenthal equation $[5,13]$ in green. Two solidification front contours $y(x)$ have been plotted, computed with the initial partition coefficient $k$ and with the modified one. The $\mathrm{k}$-modified model improves the estimation of the solidification front position, even though it is still far from the real contour. The variation of the partition coefficient has been done to simulate at the microscale the supposed effect of fluid flows on solute distribution in front of the dendritic front (cf. Section 4). However, solute distribution has finally a too small effect on solidification front behaviour to explain by itself the shape of the observed front. By taking into consideration the high thermal flow Péclet number measured at the macroscale in the weld pool and the fluid flow circulation on top side (Fig. 5a), one can suppose hot liquid can be brought to the trailing edge of the weld pool. This liquid can extend the weld pool by overheating the solidification front and make it go backward. This demonstration seems to show that, at the macroscale, the weld pool shape is probably more influenced by the transport of hot fluid at the trailing edge of the weld pool than by solute distribution effect. The effect of solute distribution is maybe more significant on the dendritic growth at the microscale.

\section{Conclusion}

Solidification during GTA welding has been investigated with the help of in situ observations. The designed setup allows the observation in the same time of the weld pool at the macroscale on both sides in visible light and on the back side in infrared light, as well as at the microscale with a high-speed camera.

Measurements have been extracted from the observations to access the parameters influencing solidification. A complete mapping of fluid flows in the weld pool has been deduced from the different measurements on two scales. The presence of fluid flow has been observed in liquid channels between primary dendrite arms in the semi-solid area.
Several hypotheses have been made on the influence of fluid flows on solidification. Fluid flows could extend the rear of the weld pool on top side by retarding solidification due to the arrival of hot liquid in the trailing edge. The fluid flows in the semi-solid area also change solidification conditions between top side and back side of the trailing edge.

To confirm the hypothesis made before, a solidification model considering welding conditions has been developed. This model, which is a combination of a solidification model and a thermal welding model, has been adapted to take into account the fluid flow conditions. Simulations made with these models using the welding conditions of the previous experiments confirm that fluid flows help to extend and give its shape to the weld pool.

\section{References}

1. Hunziker O, Dye D, Reed RC (2000) On the formation of a centreline grain boundary during fusion welding. Acta Mater 48(17):4191-4201

2. Kou S (2003) Welding metallurgy, Second edn. Wiley, Hoboken

3. Kou S (2012) Fluid flow and solidification in welding: three decades of fundamentals research at the university of Wisconsin. Weld J 91:287s-302s

4. Gandin C-A, Guillemot G, Appolaire B, Niane NT (2003) Boundary layer correlation for dendrite tip growth with fluid flow. Mater Sci Eng A 342(1-2):44-50

5. Dantzig JA, Rappaz M (2009) Solidification, First edn. EPFL Press, Lausanne

6. Kurz W, Fisher K (1992) Fundamentals of solidification, Third revi. Trans Tech Publications Ltd, Zurich

7. Boden S, Eckert S, Gerbeth G (2010) Visualization of freckle formation induced by forced melt convection in solidifying GaIn alloys. Mater Lett 64(12):1340-1343

8. Bobadilla M, Lacaze J, Lesoult G (1988) Influence des conditions de solidification sur le déroulement de la solidification des aciers inoxydables austénitiques. J Cryst Growth 89:531-544

9. Bouissou P, Pelce P (1989) Effect of a forced flow on dendritic growth. Phys Rev A 40(11):6673-6680

10. Zhao CX, van Steijn V, Richardson IM, Kleijn CR, Kenjeres S, Saldi Z (2009) Unsteady interfacial phenomena during inward weld pool flow with an active surface oxide. Sci Technol Weld Join 14(2):132-140

11. Chiocca A, Soulié F, Deschaux-Beaume F, Bordreuil C (2016) In situ observations and measurements during solidification of $\mathrm{CuNi}$ weld pools. Sci Technol Weld Join 1718(May):7

12. Kurz W, Giovanola B, Trivedi R (1986) Theory of microstructural development during rapid solidification. Acta Metall 34(5):823830

13. Nguyen NT (2004) Thermal analysis of welds. WITpress, New Forest 